\author{
Applied Mathematical Sciences, Vol. x, 20xx, no. xx, xxx - xxx \\ HIKARI Ltd, www.m-hikari.com \\ http://dx.doi.org/10.12988/
}

\title{
Soil Aridity under Climate Change and Implications for Agriculture in Italy
}

\author{
Andrea Colantoni, Lavinia M.P. Delfanti, Filippo Cossio, Benedetto Baciotti \\ Department of Agriculture, Forest, Nature and Energy (DAFNE) \\ University of Tuscia, Via S. Camillo de Lellis snc, 01100 Viterbo, Italy
}

\section{Luca Salvati}

Consiglio per la Ricerca e la sperimentazione in Agricoltura, Centre for the Study of Plant-Soil Interactions (CRA-RPS), Via della Navicella 2/4, 00184 Rome, Italy

\section{Luigi Perini}

Consiglio per la Ricerca e la Sperimentazione in Agricoltura, Unità di Ricerca per la Climatologia Ela Meteorologia Applicate all'Agricoltura, Via del Caravita 7 aRome, Italy

\section{Richard Lord}

Department of Civil \& Environmental Engineering University of Strathclyde Glasgow, UK

Copyright (C) 2014 Andrea Colantoni e Luca Salvati. This is an open access article distributed under the Creative Commons Attribution License, which permits unrestricted use, distribution, and reproduction in any medium, provided the original work is properly cited.

Corresponding Author: Andrea Colantoni; e-mail: colantoni@unitus.it

\begin{abstract}
A comprehensive temporal analysis of precipitation and temperature regimes from 1951 to 2010 has been carried out at a national and regional scale in Italy to investigate the impact of climate aridity on the agricultural system. Trends in climate aridity have also been analyzed using the UNEP aridity index, which is the ratio of rainfall to reference evapotranspiration on a yearly basis. During the
\end{abstract}


time period examined, and particularly in the most recent years, a gradual reduction in rainfall and increase in temperature have been observed, which further widened the gap between precipitation and agricultural water demand.

Keywords: Climate change, soil, agriculture, Mediterranean region.

\section{Introduction}

In recent years Italy has been experiencing growing water scarcity, related mainly to climate variations and poor management of soil and water (Brunetti et al., 2006a)., Although the possible causes and remedies are debated, it is recognized that a gradual warming process is occurring at a national scale, which is also altering the local rainfall regime [1-3].

In Mediterranean countries climate projections outline a decreased water availability, due to less abundant, irregularly distributed and more intense rainfall over the year compared to in the past [4]., Due to the particular geographical form of the country, Italy shows spatial heterogeneity in climate regimes, and thus in local climate variations. Changes in temperature and precipitation regimes are not evenly distributed but differ from place to place depending on both the underlying component of climate change associated with the atmospheric system and on the random components of weather.

One of the most important consequences of climate change for the Mediterranean environment is the increasing frequency of drought episodes and the growing impact of climate aridity on agro-forest ecosystems. Although their effects are similar, the conceptual difference between aridity and drought is equivalent to that between climate and weather. In the case of aridity, the lack of rainfall depends on the local climate and represents a permanent or seasonal condition. In contrast, drought is a transitory phenomenon related to meteorological variability and, as such, it can strike everywhere and at any time with levels of intensity and persistence which cannot be determined before [1]. 
Aridity and drought represent two sides of the same coin however: along with the long-term trends triggered by climate change in Italy there have been recurrent drought episodes recently that have affected areas previously not prone to such phenomenon, such as Northern Italy; in other areas the pre-existing water shortage has been exacerbated by the increasingly aggressive climate, as in central and southern Italy [5].

Analysis of annual and seasonal rainfall for the period 1951-2002 reveals that there has been an increase of the surface area in Italy experiencing drier rainfall regimes. Amhe most relevant cases are: the province of Foggia, where the portion of land area receiving less than $600 \mathrm{~mm}$ annual rainfall increased from $15 \%$ to $61 \%$; the province of Oristano, where a change from $8 \%$ to $76 \%$ was recorded; and the province of Nuoro, where this grew from $46 \%$ to $79 \%$. In other provinces, such as Campobasso, there has been an increase from $0 \%$ to $21 \%$, a relatively but significant trend towards drought conditions, while in the province of Grosseto the portion of land subject to reduced rainfall was unchanged at slightly less than $1 \%$. Many Italian regions are still characterized by considerable year on year variability (e.g. Salento, Central and Northern Appennine areas, South-Eastern Sicily, and even Valle D'Aosta), showing a Coefficient of Variation (CV) between 20 to $30 \%$ of the average annual rainfall. In several regions the seasonality of rainfall, typical of the Mediterranean climate, strengthens the effects and impacts of climate change: the recorded autumn-winter rainfall is three times higher than for spring-summer. In contrast, spring and summer rainfall is equal to half that of autumn-winter along the Tyrrhenian coast, while in the Northern regions and along the middle Adriatic the distribution of rainfall throughout the year is generally more evenly spread [4-5].

The above mentioned structural trends in climate aridity and increasing frequency of drought episodes, have a combined negative impact on both man and the environment, and could lead to desertification (UNCCD, 2010). Accordingly, it was necessary to carry out a regional analysis to determine the overall national pattern in terms of intensity, spatial distribution and temporal evolution of water 
shortages caused by aridity and the possible implications for the agricultural sector.

\section{Methods}

A common method for quantifying the gap between rainfall contributions and water demand is the Aridity Index (AI) which, through the formula adopted by $\mathrm{UNEP}^{1}, \mathrm{FAO}^{2}$, and $\mathrm{UNCCD}^{3}$, represents a simple but effective tool for scientific investigation, territorial monitoring and classification. The Aridity Index is calculated by dividing the total annual precipitation $(\mathrm{P})$ by the annual reference evapotranspiration (ET0):

$$
I A=P / E T O
$$

The AI index can be defined as a bioclimatic index, as it takes into account both physical phenomena (precipitation and evapotranspiration) and biological processes (plant transpiration). Moreover, the index represents one of the most relevant indicators for studying desertification processes [7-8]. As a rule, AI values below 0.5 define arid or semi-arid areas, while values over 0.65 describe humid and hyper-humid zones, as shown in the following table:

Table 1. Aridity index values

\begin{tabular}{cc}
\hline $\begin{array}{c}\text { Aridity Index }(\mathrm{Al}) \\
\text { values }\end{array}$ & $\begin{array}{c}\text { Climate } \\
\text { classification }\end{array}$ \\
\hline$A l<0.05$ & Hyper-arid \\
$0.05<A l<0.2$ & arid \\
$0.2<A l<0.5$ & Semi-arid \\
$0.5<A l<0.65$ & Dry sub-humid \\
$0.65<A l>0.75$ & humid \\
$A l>0.75$ & Hyper-humid
\end{tabular}

The meteorological data required to calculate the annual precipitation and evapotranspiration values have been gathered from the National

\footnotetext{
1 United Nations Environment Programme (http://www.unep.org/).

2 Food and Agriculture Organization (http://www.fao.org/).

${ }^{3}$ United Nations Convention to Combat Desertification (http://www.unccd.int/main.php).
} 
Agrometeorological Database $(\mathrm{BDAN})^{4}$. In order to meet the fundamental requirements of reliability, territorial coverage, uniformity, completeness, and consistency of the time series, we have chosen to use the daily data series from 1951 to 2010 for Minimum Temperature (Tn), Maximum Temperature (Tx), and Precipitation (P) processed using the geostatistical technique of Kriging at the nodes of a square grid of $30 \times 30 \mathrm{Km}$, covering the entire Italian territory. Basically, Kriging is an interpolation method to estimate, at all points across a well-defined spatial domain, the unknown value of a given parameter (in our case temperature and precipitations) using a weighted average of known values of the same parameter around the point to be estimated. Tn and Tx values were used to calculate ET0. Specificly, in this study, the estimated reference evapotranspiration was obtained using the Hargreaves/Samani formula, which requires minimum and maximum daily temperature data. Through several computational steps, the daily values of $\mathrm{P}$ and ET0 were aggregated up to the annual level and used to calculate the AI, obtaining a complete matrix of 32,640 index values (60 years x 544 grid nodes). In order to obtain information on the spatial distribution of the AI, the resulting data were processed using a GIS (Geographic Information System) after compaction of the temporal dimension obtained by calculating moving averages for 30-year windows. Hence for each grid node, mean AI values relating to the periods 1951-1980; 1952-1981; 1953-1982; 1981-2010 were obtained. This operation, besides compacting the data matrix for easier information management, has removed interannual variability in AI to reveal its spatial characteristics. As the nodes are arranged in a regular grid or uniformly, thematic mapping used the Inverse Distance Weighting (IDW) interpolation technique.

\footnotetext{
${ }^{4}$ The National Agrometeorological Data Base (BDAN) is a computerized archive designed within the National Agricultural Information System (SIAN) of the Ministry of Agriculture food and forestry policies (MiPAAF). BDAN consists of basic observation data deriving from meteorological stations belonging to various National and local monitoring networks, mainly CRA-CMA (formerly UCEA), Air Force, former Hydrographic and Mareographic Service, and several regional agrometeorological services. In addition to elementary data, BDAN includes a number of climate statistics and various agrometeorological data (www.politicheagricole.it).
} 


\section{Results and discussions}

Between 1951-2010 the national average AI value was equal to 0.90 (Table 2), meaning rainfall and evapotranspiration are almost equal. In this sense, the Country could not be considered vulnerable to the effects of aridity or drought.

Table 2. MINIMUM, AVERAGE, AND MAXIMUM ARIDITY INDEX (AI) VALUES BY ITALIAN REGION FOR THE period 1951-2010. average values and percentage variation of the ai for the periods 1951-1980 and 1981-2010.

\begin{tabular}{|c|c|c|c|c|c|c|}
\hline \multirow{2}{*}{ Region } & $1951-2010$ & $1951-1980$ & $1981-2010$ & \multirow{2}{*}{$\%$ variation } & & \\
\hline & Minimum & Average & Maximum & & & \\
\hline Abruzzo & 0.45 & 0.78 & 1.22 & 0.84 & 0.71 & -14.9 \\
\hline Basilicata & 0.45 & 0.73 & 1.08 & 0.78 & 0.68 & -13.1 \\
\hline Calabria & 0.55 & 0.93 & 1.44 & 1.01 & 0.84 & -17.1 \\
\hline Campania & 0.50 & 0.89 & 1.38 & 1.00 & 0.79 & -20.6 \\
\hline Emilia Romagna & 0.54 & 0.89 & 1.47 & 0.96 & 0.81 & -15.3 \\
\hline Friuli Venezia Giulia & 0.89 & 1.56 & 3.01 & 1.82 & 1.30 & -28.6 \\
\hline Lazio & 0.50 & 0.87 & 1.39 & 0.95 & 0.80 & -15.6 \\
\hline Liguria & 0.48 & 1.07 & 1.81 & 1.19 & 0.95 & -20.5 \\
\hline Lombardia & 0.56 & 1.16 & 2.21 & 1.32 & 1.00 & -24.2 \\
\hline Marche & 0.52 & 0.90 & 1.40 & 0.99 & 0.81 & -17.9 \\
\hline Molise & 0.48 & 0.79 & 1.25 & 0.89 & 0.69 & -22.3 \\
\hline Piemonte & 0.54 & 1.15 & 2.12 & 1.28 & 1.01 & -21.3 \\
\hline Apulia & 0.34 & 0.60 & 0.98 & 0.64 & 0.56 & -13.6 \\
\hline Sardinia & 0.29 & 0.55 & 0.96 & 0.62 & 0.48 & -22.3 \\
\hline Sicily & 0.27 & 0.56 & 0.97 & 0.57 & 0.55 & -3.4 \\
\hline Toscana & 0.52 & 0.94 & 1.62 & 1.06 & 0.82 & -22.0 \\
\hline Trentino Alto Adige & 0.73 & 1.32 & 2.39 & 1.43 & 1.20 & -16.5 \\
\hline Umbria & 0.53 & 0.92 & 1.45 & 0.99 & 0.84 & -15.2 \\
\hline Valle d'Aosta & 0.52 & 1.43 & 3.08 & 1.51 & 1.34 & -11.3 \\
\hline Veneto & 0.65 & 1.08 & 1.73 & 1.18 & 0.98 & -17.2 \\
\hline ITALY & 0.49 & 0.90 & 1.54 & 0.99 & 0.81 & -18.4 \\
\hline
\end{tabular}

During the time period investigated, complex and heterogeneous variations occurred, due to both climatic variability related to the rainfall regime and 
temperature pattern, and to peculiarities of the geographical environment of the various areas concerned (regions). For the national aggregation, AI values fluctuated between a minimum of 0.49 and a maximum of 1.54 , namely between conditions of semiarid and hyper-humid climate (table 1). A close examination of the individual regional cases demonstrates a more complex internal pattern and different situations. For example, in the case of Sicily, Sardinia, and Apulia, AI values are among the lowest in the national rankings, owing to a mean rainfall below $600 \mathrm{~mm} /$ year and evapotranspiration of almost twice this figure. Indeed, in such regions from 1951-2010 the average AI value ranges between 0.55 and 0.60, in some years reaching minimum values close to the aridity threshold $(I A<0,2)$. The northern region and part of the central region, show index values close to or higher than 1, thanks to generally more abundant rainfall, so as to counterbalance or exceed what is potentially required in terms of evapotranspiration. In these regions, however, climatic variability entailed a fluctuation of the AI between minimum values of about 0.5 and maximum values even higher than 3 (Friuli Venezia Giulia and Valle d'Aosta respectively).

Table 1 also shows an element shared by all Italian regions, namely the negative shift in AI between the 30-year periods 1951-1980 and 1981-2010. At a national scale AI decreases by over 18 percentage points, while at the regional level this ranges from a record reduction in Friuli Venezia Giulia $(-28,6 \%)$ to a minimum in Sicily $(-3,4 \%)$. Data analysis reveals that this phenomenon is commonly due to both rainfall reductions and temperature increases (and therefore evapotranspiration) that have recently heightened the pre-existing conditions of aridity and made drought periods longer. This is confirmed by the fact that the years mainly associated with low AI values have a barycenter in the period 1981-2010, while the years associated with higher values have their center of mass in the period 1951-1980. The temporal pattern of Aridity Index can be easily inferred from figure 1 , which shows the trend lines for geographical divisions of Italy (North, Center, South and Islands). The chart clearly shows that the temporal variability of the phenomena examined also shows a geographical 
gradient, being much more evident in the northern regions than in the southern ones. An Italian example of gradual drying up, is found in Sardinia and Friuli Venezia Giulia. In the second 30-year period (1981-2010), Sardinia, whose initial conditions (between 1951-1980) were not so critical $(A I=0.62 ; \mathrm{P}=870 \mathrm{~mm})$, recorded a shift in AI equal to $-22.3 \%$ which places the region below the threshold discriminating arid areas $(A I=0,48)$. In Sardinia rainfall has decreased by $42 \%$ (P = $506 \mathrm{~mm}$ ). In Friuli Venezia Giulia, AI fell -28.6\% (from 1.82 to 1.30), while the rainfall decrease was $-26.0 \%$ (from $1456 \mathrm{~mm}$ to $1080 \mathrm{~mm}$ ). Although the latter case shows a more pronounced decrease in AI from rainfall decreases equal to those of Sardinia (about $370 \mathrm{~mm} / \mathrm{year}$ ), the climate conditions in the region are still favorable, especially if compared to other regions. A full geographical comparison for the two periods is shown in Figure 2. Both maps show that most of the national territory falls within a range of AI values higher than 0.65 and, consequently, its climate can be defined as "humid" or "hyper-humid" according to the empirical classification associated with the values of the aridity index. The critical drying up phenomenon, resulting from worsening climate conditions during 1981-2010, is show to have affected the southern regions and islands.

Figure 1. Trends in the aridity index by geographical division in Italy.

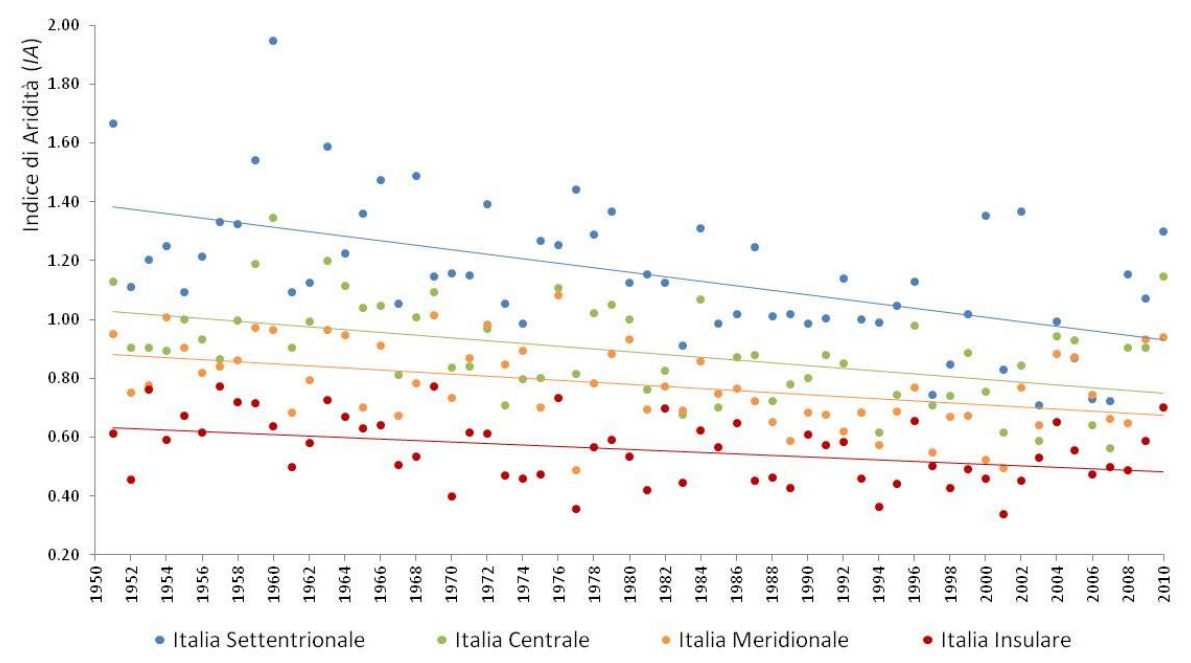

Figure 2 . The spatial distribution of the Aridity Index in Italy by time period. 

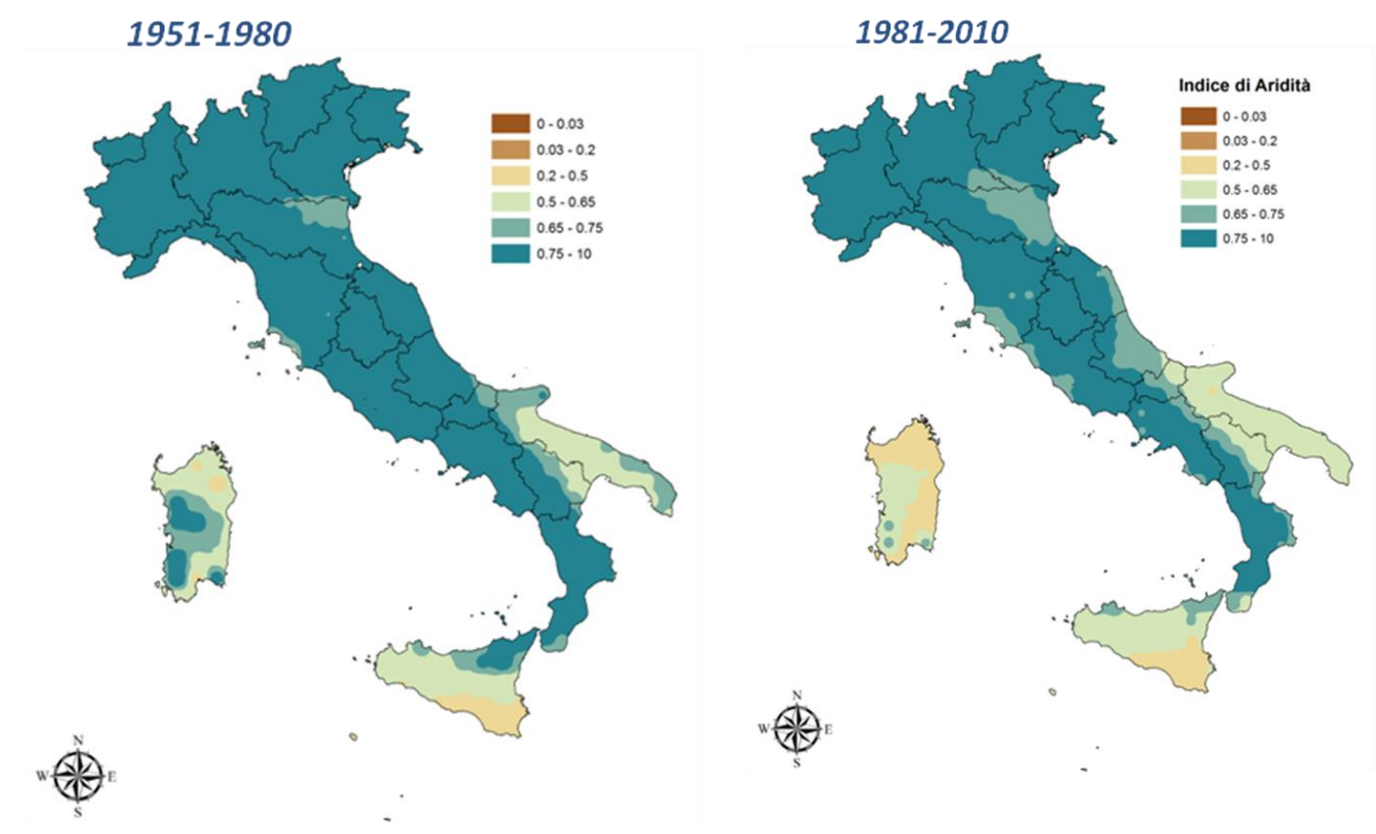

\section{Conclusions}

The data provided in this paper illustrate how Italy was affected by various degrees of water stress, mainly due to scarce rainfall and / or poorly distributed rainfall throughout the year. The main effects on the environment and on human beings have a structural nature (aridity) when related to the climate, or an occasional nature (drought) when connected to climate variability. Such a framework is then further complicated by recent climate patterns associated with falling rainfall contributions and rising temperatures. The Aridity Index (AI), is a widespread and simple tool that allowed to classify and analyze the magnitude of the aridity and drought phenomena over the national territory for a reasonable number of years (1951-2010). In addition to the absolute values and relevant climate classifications, the AI has allowed us to verify geographical characteristics and differences as well as the variations occurring. With an overall worsening during the latest 30 -year period, the most serious phenomena affect only part of the Italian territory (e.g. Sardinia and Sicily) proving marginal in other southern regions. However, we believe that by disaggregating AI values by 
season we could better describe in more detail local situations. Additional analysis revealed that throughout the year winter and autumn months are periods of rainfall surplus compared to the evapotranspiration demand (rainfall is four or more times higher than evapotranspiration). Indeed, such seasons play a crucial role in the rebuilding of water reservoirs in the soil. During spring, when the water demand is higher, rainfall is approximately equal to evapotranspiration. The exceptions are some regions of Southern Italy (especially Apulia, Sardinia, and Sicily) where even in this season the Aridity Index reveals more or less critical conditions.

During summer the lack of rain, very high temperatures and sunlight levels lead to very serious aridity and / or drought conditions that come very close to the threshold of climate hyperaridity (Sardinia and Sicily). In such season, 14 regions out of 20 have an aridity index lower than 0.5. In conclusion, since agro-ecosystems are the result of adaptation to specific environmental conditions (climate), any variation, which could alter this ecological balance, needs to be addressed by sustainable land management policies and agricultural practices.

\section{References}

[1] E.R. Cook, C. Woodhouse, C.M. Eakin, D.M. Meko, D.W. Stahle (2004) Long-Term Aridity Changes in the Western United States. Science, 306, 1015-1018

[2] M.H.I. Dore, (2005), Climate Change and Changes in Global Precipitation Patterns: What Do We Know?, Environment International 31(8): 1167-1181.

[3] A. Liberta, A. Girolamo, 1991. Geostatistical analysis of the average temperature fields in North Italy in the period 1961 to 1985. Science de la Terre Sér. Inf. Nancy 1991, 1 - 36

[4] L. Perini, L. Salvati, T. Ceccarelli, T. Caruso, A. Motisi, F.P. Marra, 2007. Atlante agroclimatico. Scenari di cambiamento climatico (Con DVD). CRA-CMA, Roma. Pag. 82. ISBN: 978-88-9014-728-9.

[5] L. Perini, L. Salvati, T. Ceccarelli, S. Sorrenti, M. Zitti, 2008. La desertificazione in Italia: Processi, Indicatori, Vulnerabilità del territorio (Con DVD). Bonanno Editore, Pag. 192. ISBN: 978-88-7796-422-9. 
[6] R.L. Belyea, K.D. Rausch, M.E. Tumbleson, Composition of corn and distillers dried grains with solubles from dry grind ethanol processing, Bioresource Technology, 94 (2004), 293 - 298.

[7] Di Trapani, A.M., Squatrito, R., M. Foderà, R. Testa, S. Tudisca and Sgroi, F., 2014. Payment for environmental services for the sustainable development of the territory. American Journal of Environmental Sciences.

[8] Sgroi, F., A.M. Di Trapani, R. Testa, and S. Tudisca, 2014. Economic sustainability of early potato production in the Mediterranean area. American Journal of Applied Sciences, 11: 1598-1603. DOI: 10.3844/ajassp.2014.1598.1603.

Received: Month xx, 20xx 